\title{
Kabuli and desi chickpeas differ in their requirement for reproductive duration
}

\author{
R. Purushothaman a,b, H.D. Upadhyaya ${ }^{a}$, P.M. Gaur ${ }^{a}$, C.L.L. Gowda ${ }^{a}$, L. Krishnamurthy ${ }^{a}, *$ \\ a International Crops Research Institute for the Semi-Arid Tropics (ICRISAT), Patancheru 502 324, Andhra Pradesh, India \\ b Jawaharlal Nehru Technological University, Hyderabad, Andhra Pradesh, India
}

\section{A R T I C L E I N F O}

\section{Article history:}

Received 7 February 2014

Received in revised form 4 April 2014

Accepted 4 April 2014

Available online $\mathrm{xxx}$

\section{Keywords:}

Adaptability

Drought stress

Reproductive duration

Root anatomy

Vegetative duration

Xylem vessels

\begin{abstract}
A B S T R A C T
There are two distinct types of chickpea (Cicer arietinum L.), called desi and kabuli, that differ in size, color and surface of seeds, flower color and morphology. Both these types are divergent geographically and broadly vary in their adaptation, nutrition, biotic and abiotic stress tolerance. In a field evaluation of large number of well-adapted $\mathrm{F}_{4}$ progenies of both desi and kabuli had shown that the grain yields were lower in all the kabulis as a consequence of lesser total shoot biomass production and lesser harvest index. The vegetative duration of kabulis was shorter and the reproductive duration extensively longer explaining why the shoot biomass productivity is low. In another field trial with a subset of the minicore chickpea germplasm, the canopy temperature depression of the kabulis were observed to be relatively lower with a low variation among the accessions and also the grain yields were lower explaining the poor adaptation of kabulis to terminal drought under Patancheru. The anatomy of roots had shown that there were quick loss of cortical layers and the presence of greater number of wider xylem vessels in kabulis relative to desis and that the kabulis were equipped to use more water with less resistance to water flow. More desi $\times$ kabuli introgressions are suggested for improving the adaptability and yield stability of kabulis under peninsular Indian environments.
\end{abstract}

(C) 2014 Elsevier B.V. All rights reserved.

\section{Introduction}

Chickpea (Cicer arietinum L.) is the third most important grain legume crop in the world, with a total production of 11.6 million tons from an area of 13.2 million ha and a productivity of $0.88 \mathrm{t} \mathrm{ha}^{-1}$ (FAOSTAT, 2011). Its seeds are protein-rich alternatives of animal protein in human diet. The domesticated chickpea has been divided into two major distinct chickpeas namely microsperma or 'desi' and macrosperma or 'kabuli' (van der Maesen, 1972; Moreno and Cubero, 1978). The seeds of desi chickpeas are usually small and dark colored with reticulated surface and the aerial plant parts usually anthocyanin pigmented bearing pink or purple flowers. In contrast, the kabulis are usually large seeded with beige color seed coat. The plant aerial parts are green that lack anthocyanin pigmentation with white flowers (Upadhyaya et al., 2008).

Cicer arietinum L. $(2 n=2 x=16)$ is the only one annual cultivated species among the nine annuals from the genus Cicer belonging to the family Fabaceae. It is self-pollinated (van der Maesen, 1987,

\footnotetext{
* Corresponding author. Tel.: +91 40 30713657; fax: +91 4030713074.

E-mail addresses: 1.krishnamurthy@cgiar.org, LKM1949@gmail.com (L. Krishnamurthy).
}

Ahmad, 2000) with the genome size of $738.09 \mathrm{Mb}$ (Varshney et al., 2013). The desi type is considered to be primitive compared to the recent origin of kabulis. Both these types had been geographically isolated for many years (Gowda et al., 1987). They are mostly distributed in South and Southeast Asia, although desi types are cultivated to some extent in Ethiopia, Mexico, and Iran. They are specifically adapted to winter sowing in the subtropics and in the hilly areas of tropics. The kabuli chickpeas are distributed mainly in the West Asia and the Mediterranean region, and adapted to spring sowing at higher latitudes.

Like many other crop plants, chickpea has a narrow genetic base that has resulted from domestication (Varshney et al., 2013). Despite vast morphological differences between the desi and kabuli germplasm, it was shown that these types were lot more common. For example, out of 1683 alleles detected in the composite collection of chickpea, 436 were common between the two types, and the frequency of common alleles between desi and kabuli types were shown to range from $47 \%$ to $54 \%$ (Upadhyaya et al., 2008). Kabuli and desi germplasm were shown to have similar mean gene diversity, while the kabuli's as a group were genetically more diverse than desis. Desis were shown to contain the largest number of unique alleles and a higher proportion of rare alleles compared to kabulis. 
Apart from morphological differences each type possesses unique characteristics. Useful characteristics had been introgressed from one type to the other (Bahl, 1988). For example, the resistance to Fusarium wilt or Helicoverpa, more frequent in desis, had been transferred to kabuli types and the resistance to Ascochyta blight from kabulis to desis (Gowda et al., 1987; Yadav et al., 2006). Greater vulnerability of the kabuli types to Helicoverpa was assigned indirectly to its relative prostrate growth habit compared to more erect desis (Yadav et al., 2006). Kabulis were listed to possess more primary branches and greater tolerance to cold, and iron deficiency than the desis (Hawtin and Singh, 1979). The nature and quantum of seed coat in these types were shown to play an important role in nutritive value, cooking time and processing quality (Singh et al., 1980). The mean seed coat percentage was reported to be 14.2 for the desis and 4.9 for the kabulis. The seed coat was shown to account for $80 \%$ of the crude fiber and all the anti nutritional polyphenols (Singh et al., 1980). The nutritive value of whole seeds of kabuli and desi types had shown that neutral detergent fiber, crude fiber and total tannins to be higher in desi types while crude protein, non fibrous carbohydrates and soluble sugars to be higher in kabuli. Overall it was shown that the nutritive value of kabuli types was higher than that of desi for ruminants (Maheri-Sis et al., 2008; Khan et al., 1995).

Candidate genes responsible for disease resistance, agronomic traits and traits that distinguish the desi and kabuli were identified (Varshney et al., 2013) and the molecular level diversity was documented using a desi $\times$ kabuli cross (Bharadwaj et al., 2011).

Consumption of desi is restricted primarily to the Middle East and Southeast Asia, whereas kabuli is a popular and valuable global commodity (Varshney et al., 2013). Extra large kabuli attracts heavy premium and is more preferred in European, North American, South African and Middle East markets with a greater export needs (Shiferaw et al., 2007). Until the eighties, kabulis were thought not to be adapted for the warmer environments such as the peninsular India. However the current crop improvement efforts in enhancing the adaptation of kabulis to the peninsular India, by transferring useful alleles from the desis, had lead not only to the release of farmer-preferred kabuli varieties such as ICCV 2 and KAK 2 but also to the development of varieties like Vihar (ICCV 95311) that are not only the kabulis but large seeded premium ones. This has become possible with the knowledge generated on the gene action and genetic variation of these types of chickpeas. However there is a clear need to generate more knowledge on the specific adaptation of these types for the best utilization of their growing niches. Therefore through this study, it is aimed to integrate the differences in adaptive requirements of these chickpea types from various recent chickpea experiments to help in fine-tuning the breeding strategy of kabulis to warmer environments.

\section{Materials and methods}

\subsection{Crop management of advanced breeding lines}

There were six advanced breeding line evaluation trials, grown adjacent to each other in a uniform field, three with desi progenies and the other three with kabuli comprising $20 \mathrm{~F}_{4}$ progenies and checks each as listed in Table 1 . These $\mathrm{F}_{4}$ progenies were the products of introgression of Fusarium wilt tolerance alleles into existing well-adapted recently released varieties from a multitude of known wilt resistant male parents. These evaluation trials were conducted in the post-rainy season of 2009-2010 on a Vertisol (fine montmorillonitic isohyperthermic typic pallustert) at ICRISAT, Patancheru $\left(17^{\circ} 30^{\prime} \mathrm{N} ; 7^{\circ} 16^{\prime} \mathrm{E}\right.$; altitude $\left.549 \mathrm{~m}\right)$, in peninsular India. The soil depth of the field used was $\geq 1.2 \mathrm{~m}$ and this soil retained about $205 \mathrm{~mm}$ of plant available water in the $120-\mathrm{cm}$ (maximum rooting depth) soil profile. The field was kept fallow except for this post-rainy season crop. These were three sets of $\mathrm{F}_{4}$ progenies each, derived from desi $\times$ desi and a kabuli $\times$ kabuli crosses that were made to further enhance wilt tolerance, seed size, early growth vigor and yield performance of recently-released, well-adapted varieties. The desi varieties intended to improve were ICCV 10, ICCC 37, JG 11 and ICCV 96029 and the kabulis were KAK 2, JGK 1, ICCV 2 and ICCV 95311. But these kabuli female parents themselves were products crosses with desis. The fields were prepared into broad bed and furrows with $1.2 \mathrm{~m}$ wide beds flanked by $0.3 \mathrm{~m}$ furrows for all the experiments. Surface application and incorporation of $18 \mathrm{~kg} \mathrm{~N} \mathrm{ha}^{-1}$ and $20 \mathrm{~kg} \mathrm{Pha}^{-1}$ as di-ammonium phosphate was carried out in all the experiments. The plot size was $4.0 \mathrm{~m} \times 4$ rows in all the experiments. The experiments were conducted in a randomized complete block design (RCBD) with four replications under purely rainfed condition. Seeds were treated with 0.5\% Benlate ${ }^{\circledR}$ (E.I. DuPont India Ltd., Gurgaon, India) + Thiram ${ }^{\circledR}$ (Sudhama Chemicals Pvt. Ltd. Gujarat, India) mixture. The experiments were sown with a 4-cone planter on 29 October 2010 in rows $30 \mathrm{~cm}$ apart and at $3-5 \mathrm{~cm}$ depth to have an estimated plant stand of at least 27 plants $\mathrm{m}^{-2}$. Intensive protection against pod borer (Helicoverpa armigera) was provided and the plots were kept weed free by manual weeding.

By regular observation, the date when $50 \%$ or more of the plants in a plot flowered was recorded as days to $50 \%$ flowering time of the plot, when $80 \%$ or more pods were yellow was recorded as physiological maturity and when $80 \%$ of the pods in a plot were dried was recorded as the time of maturity for each plot. For each chickpea plot, the time taken for pre-flowering and post-flowering periods was converted to thermal time using temperature observations in the meteorological observatory of ICRISAT, Patancheru, India. Thermal time calculation methods for the vegetative and reproductive growth duration are described in Krishnamurthy et al. (1999). At maturity, plant aerial parts were harvested at ground level from an area of $5.4 \mathrm{~m}^{2}(3.6 \times 1.5 \mathrm{~m})$ in the advanced yield trials with care to eliminate border effects in each plot, dried to constant weight in dryers equipped with high air draught at $45^{\circ} \mathrm{C}$ for $72 \mathrm{~h}$, and total shoot dry weights were recorded. Grain weights were recorded after threshing.

\subsection{Crop management of germplasm and Canopy temperature measurement}

A subset of the minicore collection of chickpea germplasm ( $n=84)$, consisting of all the highly tolerant $(n=5)$, several tolerant (53 out of 78), none of the moderately tolerant ( 0 out of 74), a few of moderately sensitive (14 out of 39) and about half of the highly sensitive (12 out of 20 ) accessions that were previously categorized based on their drought tolerance index (Krishnamurthy et al., 2010), were field-evaluated during the post-rainy season of 2010-2011 on a Vertisol. Location, soil type field preparation, basal fertilizers and crop management was as described for the advanced breeding lines trial.

The experiments were conducted in a $14 \times 6$ alpha design ( 84 accessions) with three replications and the plot size was $4.0 \mathrm{~m} \times 4$ rows. The seed was hand sown manually at a depth of $3-5 \mathrm{~cm}$ with $10 \mathrm{~cm}$ between plant with in rows and $30 \mathrm{~cm}$ between rows on 20 November 2010. About 61 seeds were used for each $4 \mathrm{~m}$ row and at 12 days after sowing (DAS) the plants were thinned maintaining a plant-to-plant spacing of $10 \mathrm{~cm}$. A sprinkler irrigation, $20 \mathrm{~mm}$, was applied immediately after sowing to ensure uniform emergence. Subsequently, plants were grown under rainfed condition. 
Table 1

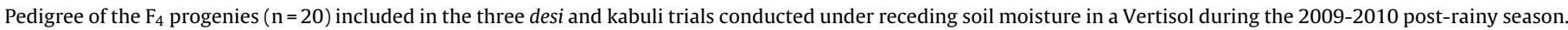

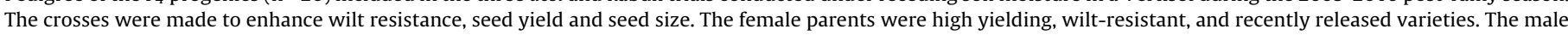
parents were diverse, high yielding and short in duration. These were wilt resistant and medium seed sized in desis and large to extra large seed sized in the kabulis.

\begin{tabular}{|c|c|c|c|c|c|c|c|}
\hline Trial/S. No & Female parent & Male parent & No. of $F_{4}$ progeny & Trial/S. No & Female parent & Male parent & No. of $\mathrm{F}_{4}$ progeny \\
\hline Desi trial 1 & & & & & Kabuli trial 1 & & \\
\hline 1 & ICCV 10 & ICC 4874 & 9 & 1 & KAK 2 & ICC 17109 & 2 \\
\hline 2 & ICCV 10 & ICC 5683 & 1 & 2 & JGK 1 & ICC 14194 & 1 \\
\hline 3 & ICCV 10 & ICC 6924 & 1 & 3 & KAK 2 & ICC 8155 & 1 \\
\hline 4 & ICCV 10 & ICC 12451 & 2 & 4 & ICCV 95311 & ICC 11883 & 1 \\
\hline 5 & ICCV 96029 & ICC 4874 & 1 & 5 & KAK 2 & ICC 17109 & 1 \\
\hline 6 & ICCC 37 & ICC 5683 & 1 & 6 & ICCV 2 & ICC 11883 & 2 \\
\hline 7 & ICCC 37 & ICC 6679 & 1 & 7 & KAK 2 & ICC 7344 & 3 \\
\hline 8 & ICCC 37 & ICC 9103 & 1 & 8 & KAK 2 & ICC 11883 & 3 \\
\hline 9 & ICCC 37 & ICC 11321 & 1 & 9 & KAK 2 & ICC 15576 & 1 \\
\hline 10 & JG 11 (check) & & 1 & 10 & ICCV 95311 & ICC 8155 & 1 \\
\hline \multirow[t]{4}{*}{11} & JAKI 9218 (check) & & 1 & 11 & KAK 2 & ICC 14202 & 1 \\
\hline & & & & 12 & ICCV 95311 & ICC 14194 & 1 \\
\hline & & & & 13 & KAK 2 (check) & & 1 \\
\hline & & & & 14 & Vihar (check) & & 1 \\
\hline Desi trial 2 & & & & & Kabuli trial 2 & & \\
\hline 1 & JG 11 & ICC 1361 & 1 & 1 & ICCV 95311 & ICC 14198 & 1 \\
\hline 2 & JG 11 & ICC 4552 & 4 & 2 & KAK 2 & ICC 14194 & 2 \\
\hline 3 & JG 11 & ICC 4874 & 5 & 3 & ICCV 2 & ICC 11883 & 1 \\
\hline 4 & JG 11 & ICC 6924 & 3 & 4 & ICCV 2 & ICC 17109 & 5 \\
\hline 5 & WR 315 & ICC 17109 & 1 & 5 & KAK 2 & ICC 14202 & 2 \\
\hline 6 & ICCV 10 & ICC 4552 & 1 & 6 & JGK 1 & ICC 17109 & 2 \\
\hline 7 & ICCV 10 & ICC 6679 & 1 & 7 & ICCV 95311 & ICC 14194 & 2 \\
\hline 8 & JG 11 & ICC 5003 & 1 & 8 & JGK 1 & ICC 14194 & 1 \\
\hline 9 & ICCC 37 (check) & & 1 & 9 & ICCV 2 & ICC 14215 & 1 \\
\hline 10 & JG 11 (check) & & 1 & 10 & JGK 1 & ICC 7344 & 1 \\
\hline \multirow[t]{2}{*}{11} & JAKI 9218 (check) & & 1 & 11 & KAK 2 (check) & & 1 \\
\hline & & & & 12 & Vihar (check) & & 1 \\
\hline Desi trial 3 & & & & & Kabuli trial 3 & & \\
\hline 1 & ICCV 10 & ICC 4552 & 1 & 1 & ICCV 2 & ICC 7344 & 2 \\
\hline 2 & ICCV 10 & ICC 4874 & 4 & 2 & ICCV 2 & ICC 14215 & 1 \\
\hline 3 & ICCV 10 & ICC 5003 & 1 & 3 & KAK 2 & ICC 11883 & 2 \\
\hline 4 & ICCV 10 & ICC 5683 & 1 & 4 & KAK 2 & ICC 14194 & 2 \\
\hline 5 & ICCV 10 & ICC 12451 & 4 & 5 & KAK 2 & ICC 15576 & 1 \\
\hline 6 & ICCV 96029 & ICC 4552 & 1 & 6 & КАК 2 & ICC 17109 & 2 \\
\hline 7 & ICCV 96029 & ICC 4874 & 1 & 7 & KAK 2 & ICC 7344 & 2 \\
\hline 8 & ICCC 37 & ICC 9103 & 1 & 8 & KAK 2 & ICC 8155 & 1 \\
\hline 9 & JG 11 & ICC 4552 & 2 & 9 & JGK 1 & ICC 17109 & 2 \\
\hline 10 & JG 11 & ICC 4874 & 1 & 10 & ICCV 95311 & ICC 11883 & 1 \\
\hline 11 & JG 11 & ICC 6924 & 1 & 11 & ICCV 95311 & ICC 14198 & 1 \\
\hline 12 & JG 11 (check) & 1 & & 12 & JGK 1 (check) & & 1 \\
\hline \multirow[t]{2}{*}{13} & JAKI 9218 (check) & 1 & & 13 & KAK 2 (check) & & 1 \\
\hline & & & & 14 & Vihar (check) & & 1 \\
\hline
\end{tabular}

\subsection{Canopy temperature}

The thermal images of plant canopies were recorded using an infrared camera, IR FLEXCAM (Infrared Solutions, Inc, USA) with a sensor size of $160 \times 120$ pixels, sensitivity of $0.09^{\circ} \mathrm{C}$ and an accuracy of $\pm 2 \%$. The target area of the image obtained was about $30 \mathrm{~cm} \times 20 \mathrm{~cm}$ at one of the central row of each plot, and the images were captured from north to avoid shading of the target area (Kashiwagi et al., 2008). The software SmartView 2.1.0.10 (Fluke Thermography), was used for the image analysis and the estimation of canopy temperatures after removing the soil (background) emissions (Zaman-Allah et al., 2011). The camera was strapped on shoulder at a height of $1.0 \mathrm{~m}$ and the observations were recorded between 1400 and $1530 \mathrm{~h}$.

Canopy temperature depression (CTD) of each genotype was estimated using the equation:

$\mathrm{CTD}=T_{\mathrm{a}}-T_{\mathrm{c}}$

$T_{\mathrm{a}}=$ air temperature $\left({ }^{\circ} \mathrm{C}\right) ; T_{\mathrm{C}}=$ canopy temperature $\left({ }^{\circ} \mathrm{C}\right)$.

CTD remained largely a negative value when the canopies are warmer than the air temperature.

\subsection{Phenology recording and final harvest}

The phenology, yield and yield components were measured as mentioned for the advanced breeding lines trial.

\subsection{Root sampling and sectioning}

At mid pod fill stage, roots of desi [ICCV 10, ICCC 37 and JG 11] and kabuli [ICCV 2, JGK 1 and KAK 2] plants that were grown under receding soil moisture, were extracted up to $20 \mathrm{~cm}$ soil depth in a Vertisol field. The tap root at this depth was of about medium in diameter and after about halfway through in branching. The root diameter variations with in a variety were visually found to be the minimum at this depth. Further, the roots of average diameter were selected for sectioning from five plants in each variety. Freehand sections of about $50 \mu \mathrm{m}$ in thickness were cut from three representative plants and the sections were stained with $50 \%$ toludine blue, a polychromatic stain that gives different colors with different tissues, and mounted in distilled water. For each variety, uniform sections from the three plants were selected for observation. Pictures were taken using an optical microscope (Olympus BX43F, Tokyo, Japan) connected to a digital camera using a $10 \times 10$ 
magnification. One photomicrograph was presented only when it almost represents all the three sections.

\subsection{Statistical analysis}

The replication-wise values of yield and yield components were used for statistical analysis of each environment using ReML considering genotypes as random. Variance components due to genotypes $\left(\sigma_{\mathrm{g}}^{2}\right)$ and error $\left(\sigma_{\mathrm{e}}^{2}\right)$ and their standard errors were determined. Environment-wise best linear unbiased predictors (BLUPs) for the advanced generation progenies or the germplasm accessions were calculated. Heritability in broad sense was estimated as $h^{2}=\sigma^{2} g /\left(\sigma^{2} g+\sigma^{2} e\right)$. The significance of genetic variability among accessions was assessed from the standard error of the estimate of genetic variance $\sigma_{\mathrm{g}}^{2}$, assuming the ratio $\sigma_{\mathrm{g}}^{2} / \mathrm{SE}\left(\sigma_{\mathrm{g}}^{2}\right)$ to follow normal distribution.

For the pooled analysis, homogeneity of variance was tested using Bartlett's test (Bartlett, 1937). Here, the plant type (desi or kabuli) or the trials $(n=6)$ were treated as a fixed effect and the breeding lines as random. The variance due to type $\times$ trial interaction $\left(\sigma_{\mathrm{gE}}^{2}\right)$ or trial $\times$ breeding lines and their standard error were determined. The significance of the fixed effect of the type or trial was assessed using the Wald statistic that asymptotically follows a $\chi^{2}$ distribution.

\section{Results and discussion}

The long term weather pattern during winter at Patancheru, India and the spring at Tel Hadya, Syria representing the desi and kabuli growing seasons, respectively, varied substantially (Fig. 1). At both the places the rainfall during these growing seasons were about minimum. At Patancheru the season is relatively drier with occasional chances of rainfall till about 30 days or after 75 DAS (Fig. 1A). The early rains may postpone the onset of terminal drought while the later ones, in the proximity of crop maturity, may not be of any use to the crop growth. But at Tel Hadya, the rainfall was well distributed during the growing season except for the later 25 days. At Patanceru, the crop is sown when the weather is warm, this weather gradually cools down as the crop reaches flowering and warms up again gradually as the crop matures. This average temperature progression exhibits a shallow boat like pattern (Fig. 1B). But at Tel Hadya, the crop is planted when it is too cool and flowers at similar temperature as that of Patancheru and matures when the weather is the warmest depicting a linear rise of temperature throughout the crop growth. It is well known that cooler temperatures delay the developmental stages in chickpea (Summerfield et al., 1990) as a consequence of requiring greater number of calendar days to aggregate the required growing degree days. Whereas the time in calendar days influence the amount of biomass accumulated during that period. Cooler temperatures also encourage more vegetative growth, both roots and shoots, and therefore kabulis under the Mediterranean take longer to flower (70 d; Silim and Saxena, 1993) with a potentially heavier root and shoot growth before entering into the reproductive phase. Therefore kabulis at Patancheru, particularly under water deficit, can be expected to suffer relatively shorter vegetative growth time (calendar days), lower shoot biomass and grain yield and a less developed root system. Therefore the vegetative growth of desi and kabuli types evolved under opposite growing temperature environments and expected to possess advantages that one type lacks. Desi chickpeas are natives of Indian subcontinent compared to the recent arrival of kabulis. Therefore as had been earlier surmised (Berger et al., 2011) their levels of adaptation can be expected to be poor.

Recently introduced varieties like ICCV 10, JG 11 and ICCV 96029 among the desis and KAK 2 (PKV Kabuli 2), JGK 1, ICCV 2 and Vihar
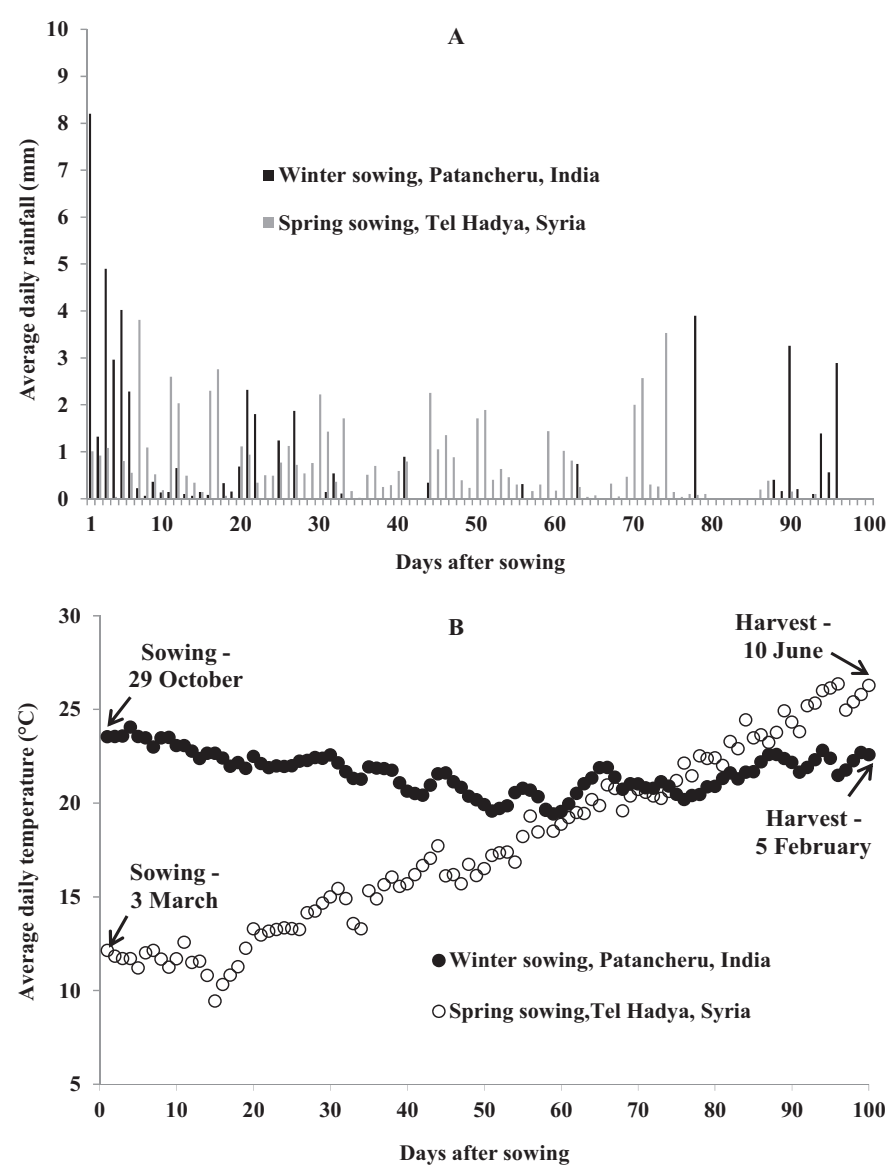

Fig. 1. Long term (2004-2013) averages of (A) daily rainfall ( $\mathrm{mm}$ ) and daily temperatures ( ${ }^{\circ} \mathrm{C}$; average of maximum and minimum) at ICRISAT, Patancheru, India and at ICARDA, Tel Hadya, Syria during the crop growing season (winter-sown crop in Patancheru and spring-sown crop in Tel Hadya). The rain fed crop growing duration for Patancheru was adopted from Krishnamurthy et al. (2013) and for Tel Hadya from Silim and Saxena (1993).

(ICCV 95311) among the kabulis are obviously the most adapted ones for the peninsular India. Though the above mentioned are categorized as kabulis, these varieties also carry desi alleles to some extent as desi parents ( $\mathrm{K} 850$ and GW 5/7) were involved. In this study, they were characterized for their thermal time requirement both for vegetative and reproductive growth phases in their native and normal niches and in a best managed, non-irrigated receding soil moisture condition. The mean vegetative degree days of the desi trials $\left(957,961\right.$ and $1008^{\circ} \mathrm{Cd}$ ) were significantly greater than the kabuli trials $\left(912,889\right.$ and $895^{\circ} \mathrm{Cd}$ ) (data not shown). Conversely the mean reproductive degree days of the desi trials (1238, 1209 and $992^{\circ} \mathrm{C}$ d) were substantially lesser than the kabuli trials (1406, 1415 and $1405^{\circ} \mathrm{Cd}$ ). Also, these means varied significantly across breeding lines within trials. The broad sense heritabilities for these characters were very high and ranged between 0.80 and 0.98 (data not shown). For desis, the best adaptation seem to require about equal or marginally more reproductive duration whereas for the kabulis it require an extended reproductive growth duration that is close to $500^{\circ} \mathrm{Cd}$ more (Fig. 2). Conversely, this requirement for an extended reproductive duration had indirectly selected for a lesser vegetative period in kabulis as this growing environment (soil moisture and temperature) had imposed ceiling to the growth period. This extent of vegetative duration seemed to proportionately reduce their shoot biomass at flowering and later. As a consequence, in spite of growing for a longer period, these kabulis were able to produce less shoot biomass as well as less grain yield (Table 2). Despite taking relatively longer time for the 
Table 2

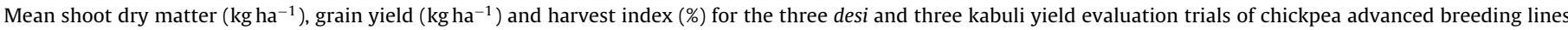
$(n=20)$ in the 2009-2010 post-rainy season under terminal drought stressed conditions.

\begin{tabular}{|c|c|c|c|c|c|}
\hline Season/environment & Trial mean & Range of predicted means & S.Ed & $\sigma_{\mathrm{g}}^{2}(\mathrm{SE})$ & Heritability $\left(h^{2}\right)$ \\
\hline \multicolumn{6}{|l|}{ Desi trial 1} \\
\hline Shoot dry matter $\left(\mathrm{kg} \mathrm{ha}^{-1}\right)$ & 5091 & $5063-5114$ & 68.2 & $2514(12,499)$ & 0.074 \\
\hline Grain yield $\left(\mathrm{kg} \mathrm{ha}^{-1}\right)$ & 2837 & $2685-2941$ & 105.1 & $10,823(7474)$ & 0.490 \\
\hline Harvest index (\%) & 55.7 & 51.5-60.7 & 1.09 & $6.34(2.27)$ & - \\
\hline \multicolumn{6}{|l|}{ Desi trial 2} \\
\hline Shoot dry matter $\left(\mathrm{kg} \mathrm{ha}^{-1}\right)$ & 4788 & $4442-5124$ & 188.5 & $41,726(24,270)$ & 0.574 \\
\hline Grain yield $\left(\mathrm{kg} \mathrm{ha}^{-1}\right)$ & 2819 & $2447-3130$ & 137.6 & $43,394(18,151)$ & 0.782 \\
\hline Harvest index (\%) & 58.8 & $50.4-63.5$ & 1.22 & $12.12(4.19)$ & - \\
\hline \multicolumn{6}{|l|}{ Desi trial 3} \\
\hline Shoot dry matter $\left(\mathrm{kg} \mathrm{ha}^{-1}\right)$ & 5132 & $4850-5311$ & 147.2 & $22,370(14,605)$ & 0.516 \\
\hline Grain yield $\left(\mathrm{kg} \mathrm{ha}^{-1}\right)$ & 2917 & $2791-3026$ & 105.9 & $9054(8197)$ & 0.381 \\
\hline Harvest index (\%) & 56.9 & $53.7-58.9$ & 1.87 & $4.75(2.50)$ & - \\
\hline \multicolumn{6}{|l|}{ Kabuli trial 1} \\
\hline Shoot dry matter $\left(\mathrm{kg} \mathrm{ha}^{-1}\right)$ & 4506 & $4155-4908$ & 648.2 & $52,625(22,203)$ & 0.775 \\
\hline Grain yield $\left(\mathrm{kg} \mathrm{ha}^{-1}\right)$ & 2202 & 814-2628 & 311.4 & $43,138(16,741)$ & 0.840 \\
\hline Harvest index (\%) & 49.0 & $37.7-55.8$ & 1.89 & $29.28(10.12)$ & - \\
\hline \multicolumn{6}{|l|}{ Kabuli trial 2} \\
\hline Shoot dry matter $\left(\mathrm{kg} \mathrm{ha}^{-1}\right)$ & 4633 & $4224-4983$ & 773.1 & $63,640(30,463)$ & 0.689 \\
\hline Grain yield $\left(\mathrm{kg} \mathrm{ha}^{-1}\right)$ & 2238 & $1845-2525$ & 302.8 & $56,233(21,076)$ & 0.868 \\
\hline Harvest index (\%) & 48.5 & $37.6-57.1$ & 2.01 & $39.0(13.02)$ & - \\
\hline \multicolumn{6}{|l|}{ Kabuli trial 3} \\
\hline Shoot dry matter $\left(\mathrm{kg} \mathrm{ha}^{-1}\right)$ & 4507 & $4182-4904$ & 159.7 & $47,621(22,571)$ & 0.732 \\
\hline Grain yield $\left(\mathrm{kg} \mathrm{ha}^{-1}\right)$ & 2187 & $1985-2446$ & 94.4 & $22,313(9625)$ & 0.800 \\
\hline Harvest index (\%) & 48.6 & $42.9-53.4$ & 1.84 & $10.28(4.24)$ & - \\
\hline
\end{tabular}

reproductive growth and with enough time for pod fill, the kabulis had possessed poor harvest indices too (Table 2). Overall, kabulis were able to produce only $88 \%$ of the shoot biomass and $77 \%$ of the grain yield and with a short fall of $7-10 \%$ in harvest indices. These phenomena of requirement for a relatively longer reproductive period can be speculated to be much more intense in true kabulis.

Overall (considering both the desi and kabuli trials together), the mean vegetative duration was positively associated both with the mean total shoot biomass produced and with the mean grain yield indicating that the final productivity is limited by the shoot biomass produced at flowering due to a shorter vegetative growth period as in kabulis (Fig. 3). In the same line, the reproductive duration was negatively associated both with the total shoot biomass produced and the grain yield. It is likely that the large-seeded kabulis need longer periods for grain filling as these have evolved in a region where the seed filling occurred in autumn when the temperatures and evapotranspirational demand were high with a rapid rate of seed filling and a rapid accrual of degree days. Once such types were

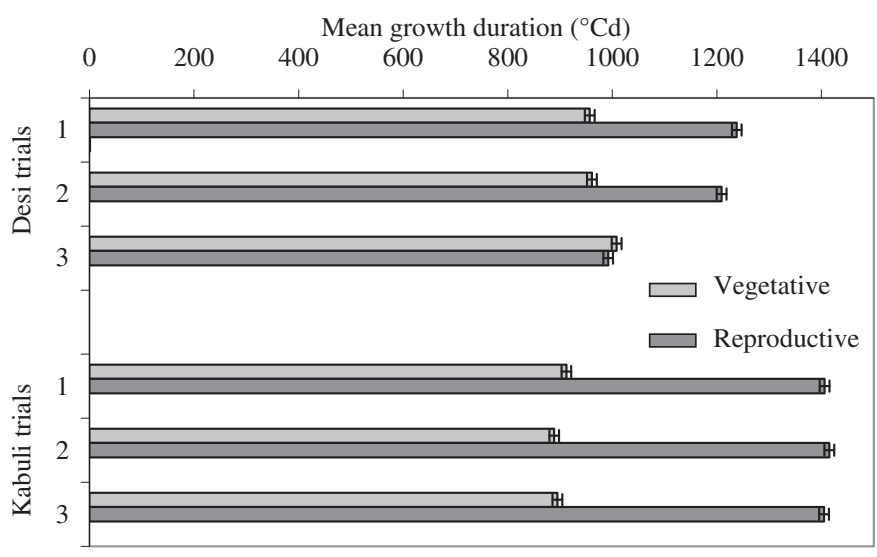

Fig. 2. Mean vegetative and reproductive growth durations (degree days) of both desi and kabuli breeding trials under terminal drought prone receding soil moisture conditions in a Vertisol during 2009-2010, Patancheru, India. required to fill in their seeds under relatively lower temperatures, the process would take longer in calendar days. When terminal water deficit fixes a ceiling for such an extended period of seed filling, it reflects on reduced grain yield through reduced seed number, seed size and harvest index.
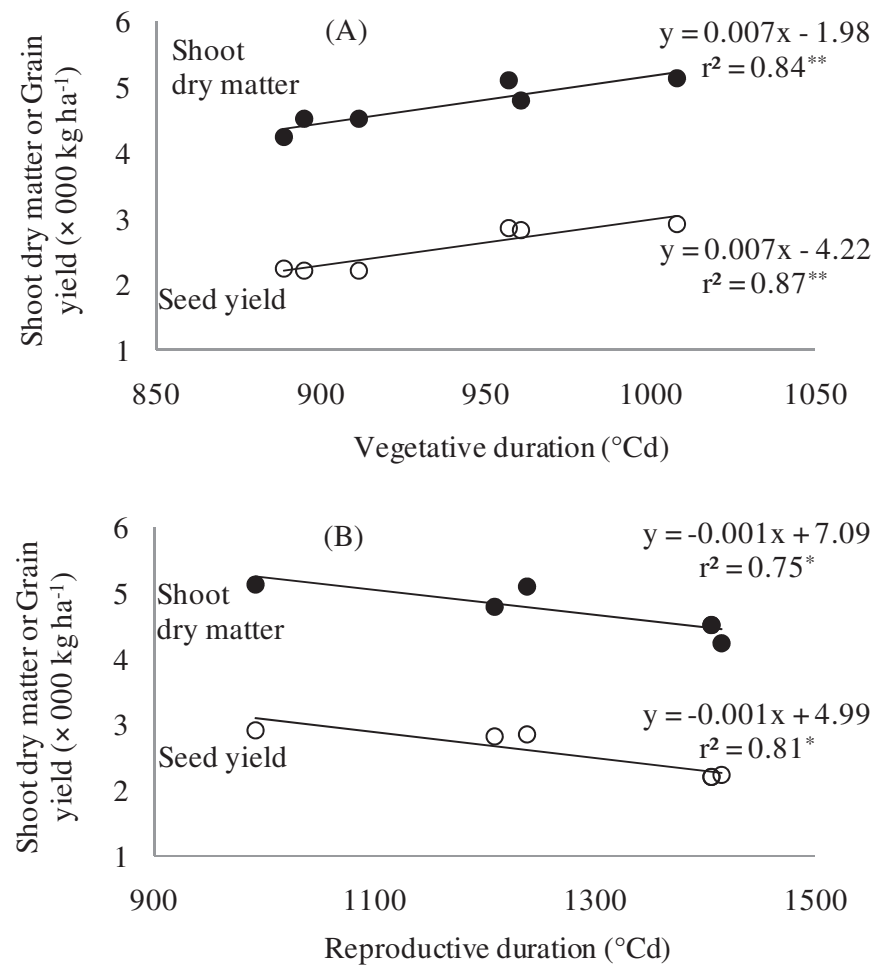

Fig. 3. Relationship between the $(\mathrm{A})$ vegetative growth duration $\left({ }^{\circ} \mathrm{Cd}\right)$ and the trial mean of total shoot dry matter (closed circles) or trial mean of grain yield (open circles) and (B) reproductive growth duration $\left({ }^{\circ} \mathrm{Cd}\right)$ and the trial mean of total shoot dry matter (closed circles) or trial mean of grain yield (open circles) of six trials of chickpea advanced breeding lines, 2009-2010 post-rainy season, ICRISAT center, Patancheru, India. 
Table 3

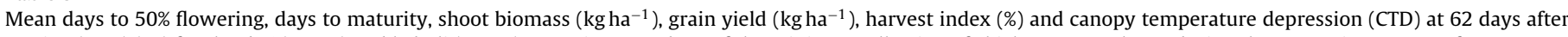

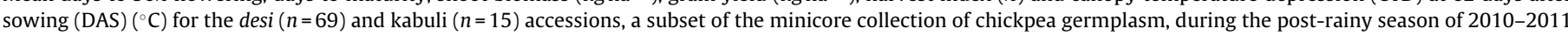
under drought-stressed environment.

\begin{tabular}{|c|c|c|c|c|c|}
\hline Type & Trial mean & Range of predicted means & S.Ed & $\sigma_{\mathrm{g}}^{2}(\mathrm{SE})$ & Heritability $\left(h^{2}\right)$ \\
\hline \multicolumn{6}{|l|}{ Desi } \\
\hline Days to $50 \%$ flowering & 45.7 & $31.8-65.7$ & 2.01 & $64.18(11.9)$ & 0.969 \\
\hline Days to maturity & 89.8 & 85.0-104.9 & 2.11 & $18.5(3.79)$ & 0.880 \\
\hline Shoot biomass $\left(\mathrm{kg} \mathrm{ha}^{-1}\right)$ & 3955 & $2865-4735$ & 277.6 & $149,692(36,801)$ & 0.743 \\
\hline Grain yield $\left(\mathrm{kg} \mathrm{ha}^{-1}\right)$ & 1830 & $783.7-2405$ & 168.1 & $158,691(31,349)$ & 0.911 \\
\hline Harvest index (\%) & 46.4 & 23.2-58.1 & 2.26 & $80.0(14.8)$ & 0.968 \\
\hline CTD at 62 DAS $\left({ }^{\circ} \mathrm{C}\right)$ & -2.30 & $-4.51--0.67$ & 0.56 & $0.73(0.17)$ & 0.785 \\
\hline \multicolumn{6}{|l|}{ Kabuli } \\
\hline Days to $50 \%$ flowering & 47.0 & $39.6-57.1$ & 2.72 & $33.6(14.3)$ & 0.890 \\
\hline Days to maturity & 92.2 & $86.4-97.0$ & 1.16 & $10.65(4.30)$ & 0.937 \\
\hline Shoot biomass $\left(\mathrm{kg} \mathrm{ha}^{-1}\right)$ & 3974 & $3042-4529$ & 342 & $198,851(108,778)$ & 0.706 \\
\hline Grain yield $\left(\mathrm{kg} \mathrm{ha}^{-1}\right)$ & 1463 & $1218-1721$ & 164 & $32,413(21,727)$ & 0.587 \\
\hline Harvest index (\%) & 37.2 & $26.4-49.8$ & 1.87 & $45.4(17.8)$ & 0.961 \\
\hline CTD at 62 DAS $\left({ }^{\circ} \mathrm{C}\right)$ & -2.61 & $-2.64--2.58$ & - & $-0.009(0.11)$ & 0.037 \\
\hline
\end{tabular}

Another important aspect of difference between these two types of chickpea is the canopy temperature depression variation observed during 2010-2011. The kabuli entries were few in this trial for making a good comparison. Nevertheless, the mean $50 \%$ flowering and maturity variation of all the accessions included in this trial was not that large. But overall the grain yield and harvest indices of desi were greater than that of kabulis while the mean shoot biomass was similar. Successfully well-adapted chickpea germplasm was able to keep its canopy cooler than that of the less successful accessions and lead to greater grain yield productivity. The desi germplasm varied extensively for this trait and the CTD ranged between -4.51 and -0.67 whereas the kabuli germplasm had a narrow range of $-2.64--2.58$ (Table 3 ). Also the yield levels were very low indicating that the root system is relatively less effective in supply of water. A significant regression of CTD recorded at 62 DAS with grain yield was limited to desi types explaining about $43 \%$ variation of the association but similar regression with only kabulis explained a very minimal $6 \%$ closeness of fit (Fig. 4). The poor fit in kabulis was primarily due to a narrow range of variation in CTD, more toward the lower side.

Kabuli evolution has occurred in an environment where the later part of the podfill occurs at a constantly warming environment facing a situation of forced maturity and accruing degree days rapidly. Conversely, under relatively cooler environments, they tend to require longer calendar days for their reproductive phase. Therefore, extensive genetic modification is required to improve the adaptation of kabulis. Also management options of early sowing can largely help to realize better yields under peninsular India.

2010-11

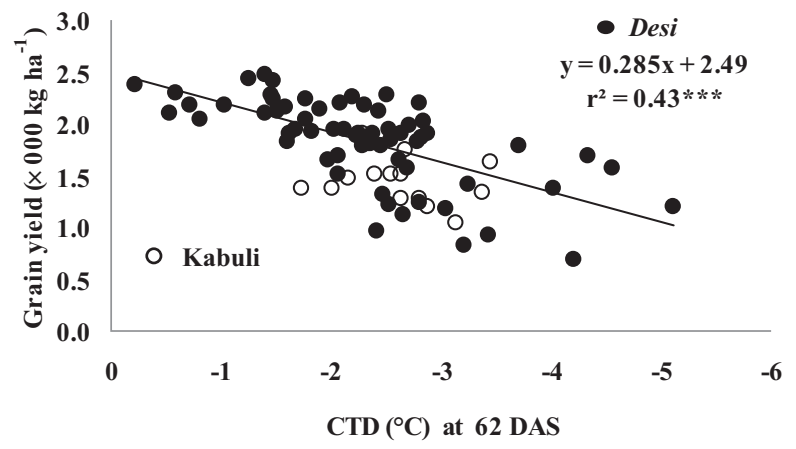

Fig. 4. The relationship between canopy temperature depression (CTD) recorded at 62 days after sowing (DAS) and the grain yield of both the desi (closed circles) and kabuli (open circles) accessions in a subset of the minicore collection $(n=84)$ during the post-rainy season of 2010-2011 under drought-stressed environment.
Roots are in direct contact with the soil and the shoot and therefore the water conducting xylem vessels in roots are expected to give a clue on their capacity in water uptake influencing the ability to tolerate drought. The thickness of the tap root varied heavily and it varied minimum at $20 \mathrm{~cm}$ soil depth across plants within a variety. Nevertheless, it was difficult to characterize the varieties for root thickness that was ranging heavily (data not shown). The transverse sections of the tap root from a soil depth of $20 \mathrm{~cm}$ revealed that the cortex is mostly getting narrowed down with the advancing of secondary thickening of the vascular tissue. Such a reduction or loss in cortical tissue was greater in kabulis than in desis (Fig. 5). The cortex was intact and prominent in desis and particularly in varieties ICCV 10 and JG 11 . Based on the three replicates of root transverse sections sampled for root anatomy it was noted that the xylem vessels in desis were fewer in number and narrower in diameter compared to the kabulis (data not shown). The wider metaxylem vessels were 21, 34 and 45 in desi varieties ICCV 10, ICCC 37 and JG 11, respectively, compared to 57, 51 and 50 in the kabuli varieties ICCV 2, JGK 1 and KAK 2 (Fig. 5). Similarly the protoxylem vessels were 43,31 and 70 in desi varieties ICCV 10, ICCC 37 and JG 11, respectively, compared to 90, 90 and 85 in the kabuli varieties ICCV 2, JGK 1 and KAK 2. Average metaxylem diameter (mean of three widest and three narrowest) of desis were 50.4, 75.5, and 71.2 $\mu \mathrm{m}$ for ICCV 10, ICCC 37 and JG 11 and of kabulis was 78.0, 78.5, and 76.0 $\mu \mathrm{m}$ for ICCV 2, JGK 1 and KAK 2 , respectively. Though existence of conclusive differences cannot be drawn on the basis of root diameters and cortical thickness between desis and kabulis, it is clearly noticeable that the kabulis possessed greater number of wider xylem vessels. Conduit number and diameter had been shown to be the two principal determinants of water flow, closely following the estimates of Hagen-Poiseuille equation that envisages conductance per tube to be proportional to the capillary diameter raised to the fourth power (Zimmerman, 1983; Gibson et al., 1984). The resistance to the longitudinal flow of water through the seminal roots of a wheat plant was shown to depend on the number of seminal axes and on the diameters of their main xylem vessels (Richards and Passioura, 1981). A breeding program, with limited success, was also carried out in wheat to moderate water uptake through selection of narrower vessels (Richards and Passioura, 1989). It had also been shown that the legume genera are typical in their number and width of xylem vessels explaining their adaptation to certain moisture environments, water requirements/uptake and the nature of drought tolerance (Purushothaman et al., 2013). Also it had been demonstrated that the vascular bundle development during secondary root thickening was heavily sensitive to water deficits and the number and width of xylem vessels increase to decrease the resistance in water flow 

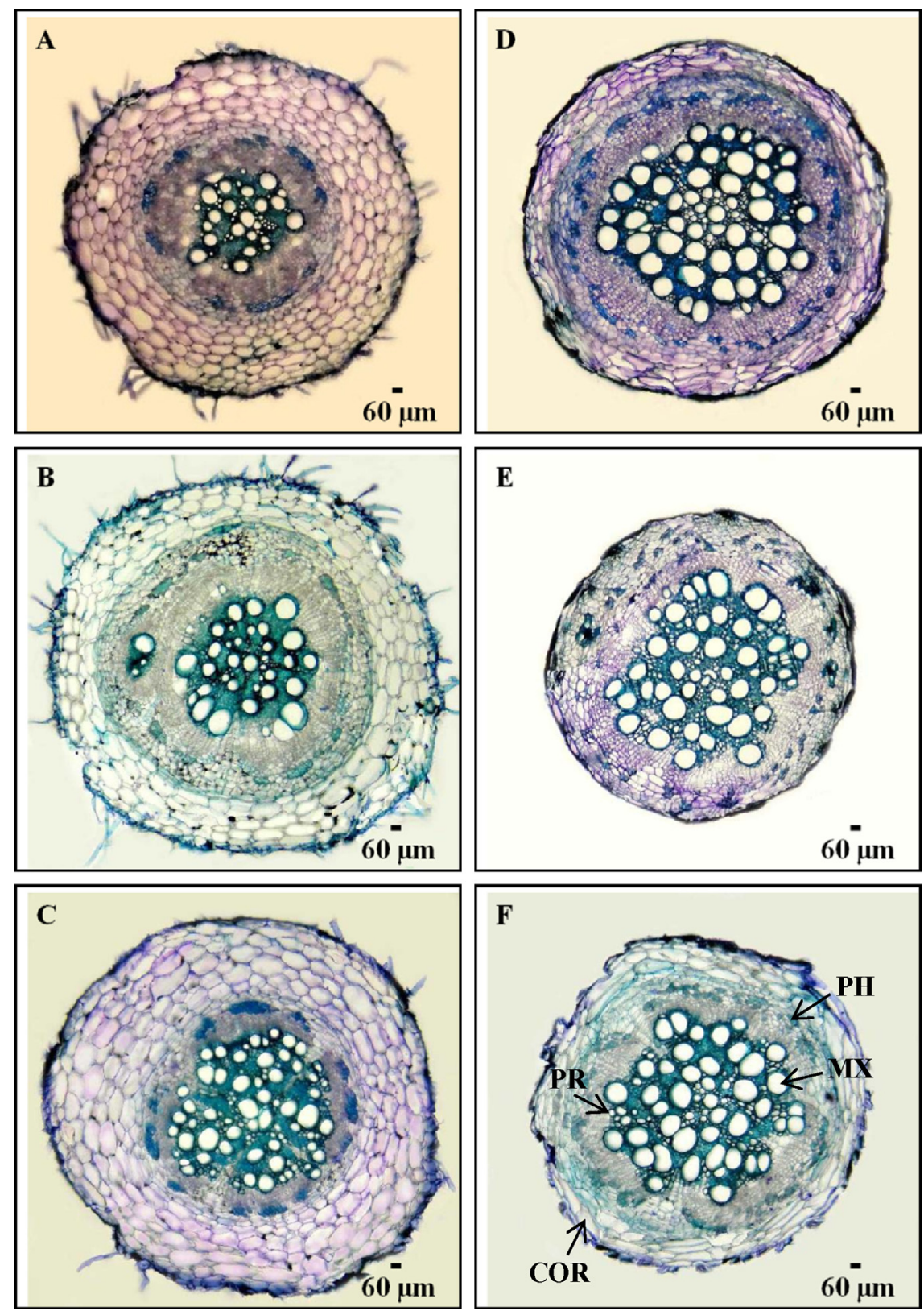

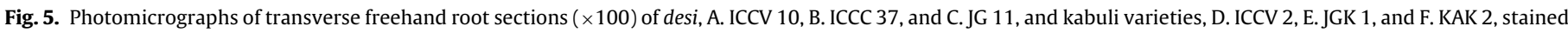
with $50 \%$ toludine blue. $\mathrm{COR}=$ Cortex, $\mathrm{MX}=$ Metaxylem, $\mathrm{PR}=$ Protoxylem, $\mathrm{PH}=$ Phloem.

as an adaptive strategy toward drought. On this basis of such predictions, desis seem to moderate their water flow or uptake and are conservative in their water requirement adapting well to the receding soil moisture environments than the kabulis that have access to more water during the major part of their early growth (Berger et al., 2004).

In a very early desi $\times$ kabuli introgression effort, no significant yield improvements could be obtained by this inter-type introgression under peninsular Indian environment and the maximum advantage this brought about was early vegetative growth vigor in some segregants (Gowda et al., 1987). But parallel efforts in the northern latitudes of the Indian subcontinent, in recombining kabuli and desi germplasms using single, 2-way, or double crosses, have yielded several high-yielding and widely adapted varieties such as L 104, L 144, L 550, and Pusa 267 among kabuli types and Pusa 244, Pusa 256, and Pusa 261 among desis (Bahl, 1988). But over the years kabuli improvement had gone a long way and well-adapted, bold-seeded kabuli varieties such as Vihar, carrying desi alleles from genotypes K 850 and GW 5/7, is released for use in peninsular India. The growing environment needs to support extended reproductive growth duration (devoid of terminal drought and heat) so as to realize the maximum advantage of the kabuli alleles. This should bring awareness to transgress relevant alleles from desi types to enhance kabuli adaptation to peninsular India.

\section{Conclusions}

The desi and kabuli type chickpeas have evolved in different environments experiencing relatively opposite temperature regimes and therefore greater adaptation to peninsular India and yield stability requires yet more genetic enhancement efforts with more alleles from the desis. The kabulis potentially require a longer reproductive phase and their canopy temperature tends to be warmer than the well-adapted desis making their productivity 
lower and less tolerant to drought. There are anatomical evidences to prove that kabulis are equipped to use more water and offer less resistance to water flow.

\section{Acknowledgements}

The weather data for Tel Hadya, Syria provided by Dr Chandrashekhar Biradar, Geoinformatics, ICARDA and the technical support of $\mathrm{Mr}$ J. Shankaraiah in managing the field experiments are gratefully acknowledged.

\section{References}

Ahmad, F., 2000. A comparative study of chromosome morphology among the annual Cicer species. Cytobios 101, 37-53.

Bahl, P.N., 1988. Chickpea. In: Baldev, B., Ramanujum, S., Jain, H.K. (Eds.), Pulse Crops. Oxford and IBH publishing Co. Pvt. Ltd., New Delhi, India, pp. 95-131.

Bartlett, M.S., 1937. Properties of sufficiency and statistical tests. Proc. R. Soc. Lond. A $160,268-282$

Berger, J.D., Milroy, S.P., Turner, N.C., Siddique, K.H.M., Imtiaz, M., Malhotra, R., 2011. Chickpea evolution has selected for contrasting phenological mechanisms among different habitats. Euphytica 180, 1-15.

Berger, J.D., Turner, N.C., Siddique, K.H.M., Knights, E.J., Brinsmead, R.B., Mock, I., Edmondson, C., Khan, T.N., 2004. Genotype by environment studies across Australia reveals the importance of phenology for chickpea (Cicer arietinum L.) improvement. Aus. J. Agric. Res. 55, 1071-1084

Bharadwaj, C., Chauhan, S.K., Yadav, S., Satyavathi, C.T., Singh, R., Kumar, J., Srivastava, R., Rajguru, G., 2011. Molecular marker-based linkage map of chickpea (Cicer arietinum) developed from desi $\times$ kabuli cross. Indian J. Agric. Sci. 81, $116-118$.

FAOSTAT., 2011. Statistical database 2011. Available at: http://faostat.fao.org/ site/567/DesktopDefault.aspx?PageID=567\#ancor

Gibson, A.C., Calkin, H.W., Nobel, P.S., 1984. Xylem anatomy, water flow, and hydraulic conductance in the fern Cyrtomium falcatum. Am. J. Bot. 71, 564-574.

Gowda, C.L.L., Rao, B.V., Chopra, S., 1987. Utility of desi $\times$ kabuli crosses in chickpea improvement. Int. Chickpea Newsl. 17, 4-6.

Hawtin, G.C., Singh, K.B., 1979. Kabuli-desi introgression: problems and prospects. In: Green, J.M., Nene, Y.L., Smithson, J.B. (Eds.), Proceedings of the International Workshop on Chickpea Improvement. 28 Feb-2 Mar 1979, Hyderabad, A.P., India, pp. 51-60.

Kashiwagi, J., Krishnamurthy, L., Upadhyaya, H.D., Gaur, P.M., 2008. Rapid screening technique for canopy temperature status and its relevance to drought tolerance improvement in chickpea. J. SAT Agric. Res. 6, 1-4.

Khan, M.A., Akthar, N., Ullah, I., Jaffery, S., 1995. Nutritional evaluation of desi and kabuli chickpeas and their products commonly consumed in Pakistan. Int. J. Food Sci. Nutr. 46, 215-223.

Krishnamurthy, L., Johansen, C., Sethi, S.C., 1999. Investigation of factors determining genotypic differences in seed yield of nonirrigated and irrigated chickpea using a physiological model of yield determination. J. Agron. Crop Sci. 183, 9-17.

Krishnamurthy, L., Kashiwagi, J., Gaur, P.M., Upadhyaya, H.D., Vadez, V., 2010. Sources of tolerance to terminal drought in the chickpea (Cicer arietinum L.) minicore germplasm. Field Crop Res. 119, 322-330.
Krishnamurthy, L., Kashiwagi, J., Upadhyaya, H.D., Gowda, C.L.L., Gaur, P.M., Singh S., Purushothaman, R., Varshney, R.K., 2013. Partition coefficient - a trait that contributes to drought tolerance in chickpea. Field Crop Res. 149, 354-365.

Maheri-Sis, N., Chamani, M., Sadeghi, A.A., Aghazadeh, A., Aghajanzadeh-Golshani, A., 2008. Nutritional evaluation of kabuli and desi type chickpeas (Cicer arietinum L.) for ruminants using in vitro gas production technique. Afr. J. Biotechnol. 7 2946-2951.

Moreno, M., Cubero, J.I., 1978. Variation in Cicer arietinum L. Euphytica 27, 465-485

Purushothaman, R., Zaman-Allah, M., Mallikarjuna, N., Pannirselvam, R., Krishnamurthy, L., Gowda, C.L.L., 2013. Root anatomical traits and their possible contribution to drought tolerance in grain legumes. Plant Prod. Sci. 16, $1-8$.

Richards, R.A., Passioura, J.B., 1981. Seminal root morphology and water use of wheat I. Environmental effects. Crop Sci. 21, 249-252.

Richards, R.A., Passioura, J.B., 1989. A breeding program to reduce the diameter of the major xylem vessel in the seminal roots of wheat and its effect on grain yield in rain-fed environments. Aust. J. Agric. Res. 40, 943-950.

Shiferaw, B., Jones, R., Silim, S., Tekelewold, H., Gwata, E., 2007. Analysis of Production Costs, Market Opportunities and Competitiveness of Desi and Kabul Chickpeas in Ethiopia. IPMS (Improving Productivity and Market Success) of Ethiopian Farmers Project Working Paper 3. International Livestock Research Institute, Nairobi, Kenya, pp. 48.

Silim, S.N., Saxena, M.C., 1993. Adaptation of spring-sown chickpea to the Mediterranean basin. I. Response to moisture supply. Field Crop Res. 34 121-136.

Singh, U., Kumar, J., Jambunathan, R., Smithson, J.B., 1980. Variability in the seed coat content of desi and kabuli chickpea cultivars, 3. Int. Chickpea Newsl., pp. 18.

Summerfield, R.J., Virmani, S.M., Roberts, E.H., Ellis, R.H., 1990. Adaptation of chickpea to agroclimatic constraints. In: van Rheenen, H.A., Saxena, M.C. (Eds.) Chickpea in the Nineties. ICRISAT, Patancheru, India, pp. 61-72.

Upadhyaya, H.D., Dwivedi, S.L., Baum, M., Varshney, R.K., Udupa, S.M., Gowda, C.L.L. Hoisington, D., Singh, S., 2008. Genetic structure, diversity, and allelic richness in composite collection and reference set in chickpea (Cicer arietinum L.). BMC Plant Biol. 8, 106

van der Maesen, L.J.G., 1972. Cicer L., A Monograph of the Genus, with Special References to Chickpea (Cicer arietinum L.). Its Ecology and Cultivation. Mededlingen landbouw hogeschool (Communication Agricultural University), Wageningen.

van der Maesen, L.J.G., 1987. Origin, history and taxonomy of chickpea. In: Saxena, M.C. Singh, K.B. (Eds.), The Chickpea. CAB Int. Publ., UK, pp. 11-34.

Varshney, R.K., Song, C., Saxena, R.K., Azam, S., Yu, S., Sharpe, A.G., Cannon, S., Baek, J., Rosen, B.D., Tar'an, B., Millan, T., Zhang, X., Ramsay, L.D., Iwata, A., Wang, Y., Nelson, W., Farmer, A.D., Gaur, P.M., Soderlund, C., Penmetsa, R.V., Xu, C., Bharti, A.K., He, W., Winter, P., Zhao, S., Hane, J.K., Carrasquilla-Garcia, N., Condie, J.A., Upadhyaya, H.D., Luo, M.C., Thudi, M., Gowda, C.L.L., Singh, N.P., Lichtenzveig, J., Gali, K.K., Rubio, J., Nadarajan, N., Dolezel, J., Bansal, K.C., Xu, X., Edwards, D., Zhang, G., Kahl, G., Gil, J., Singh, K.B., Datta, S.K., Jackson, S.A., Wang, J., Cook, D.R. 2013. Draft genome sequence of chickpea (Cicer arietinum) provides a resource for trait improvement. Nat. Biotechnol. 31, 240-248.

Yadav, S.S., Kumar, J., Yadav, S.K., Singh, S., Yadav, V.S., Turner, N.C., Redden, R., 2006 Evaluation of Helicoverpa and drought resistance in desi and kabuli chickpea. PGR 4, 198-203.

Zaman-Allah, M., Jenkinson, D.M., Vadez, V., 2011. A conservative pattern of water use, rather than deep or profuse rooting, is critical for the terminal drought tolerance of chickpea. J. Exp. Bot. 62, 4239-4252.

Zimmerman, M.H., 1983. Xylem Structure and the Ascent of Sap. Springer-verlag, Berlin. 